\title{
The Risk Factor Atherosclerosis in Ageing for Heart Attacks
}

\section{S. Bhagyalakshmi ${ }^{1}$, M. V. Sailaja *2, Vijitha ${ }^{3}$.}

${ }^{1}$ Associate professor, Department of physiology, SV M edical College, Tirupati, Andhra Pradesh, India.

${ }^{* 2}$ Associate professor, Department of physiology, Viswabharati M edical College, Kurnool, Andhra Pradesh, India.

${ }^{3}$ Associate professor, Department of physiology, ACSR Govt. Medical College, Nellore, Andhra Pradesh, India.

\section{ABSTRACT}

\begin{abstract}
Ageing is a normal physiological process characterized by alterations in cell and tissue structures associated with a reduction in functional capacity-physical, sexual, mental. More than $80 \%$ of all deaths due to cardiovascular diseases occur in elderly people above 60 years. Coronary artery disease is also associated with ageing and is likely to involve multiple vessels, mainly left coronary artery and there is a graded and progressive reduction in the homeostatic reserve function of organs and systems. Consistent changes in the autonomic system accompany ageing and influence cardiovascular function. Atherosclerosis is a chronic inflammatory process of the arterial wall induced by endogenous toxic plasma lipid components; it is a major initiator of thrombosis related to abnormal vascular flow and loss of endothelial vascular integrity. In our study we examined 20 males aged 50 to 70 years with hyper tension (Smokers \& alcoholics) and 20 normal healthy individuals aged between 40 to 49 years are controls. aged between 40 to 49 years are controls. Blood pressure recording was done and Lipid Profile was estimated from the both groups. The SBP and DBP was found to be greater in aged group when compared with control group which can be attributed to changes in large arteries include stiffness of elastic tissue with much thicker and less flexible walls. This causes the increase force of ventricular contraction and SBP. The increase in large vessel stiffness plays a central patho physiological role in hypertension in older individuals. The lipid levels of the subjects is greater than the controls due to increase in plasma or serum lipid levels. This indicates the risk factor atherosclerosis related with ageing. This is one of the predisposing factors for heart attacks and cerebral strokes.
\end{abstract}

KEY WORDS: Lipid Profile, Atherosclerosis, Endothelium, SBP, DBP, Echo.

Address for correspondence: Dr. M.V.Sailaja, Associate professor, Department of physiology, Viswabharati M edical College, Kurnool, Andhra Pradesh, India. E-Mail: kvsailaja74@gmail.com

\begin{tabular}{|l|ll|}
\hline \multicolumn{3}{|c|}{ Online Access and Article Informtaion } \\
\hline Quick Response code & \multicolumn{2}{|c|}{ International Journal of Integrative Medical Sciences } \\
\cline { 2 - 3 } & \multicolumn{2}{|c|}{ www.imedsciences.com } \\
\cline { 2 - 3 } & Received: 13-07-2015 & Accepted: 27-07-2015 \\
Dol: $10.16965 /$ ijims.2015.120 & Reviewed: 13-07-2015 & Published: 31-07-2015 \\
\hline Source of Funding: Self & \multicolumn{2}{|c|}{ Conflicts of interest: None } \\
\hline
\end{tabular}

\section{INTRODUCTION}

Coronary artery disease is quite common in ageing and is likely to involve multiple vessels and mainly the left coronary artery. M ore than $80 \%$ of all deaths due to cardiovascular diseases occur in elderly people above 60 years. Cardiovascular ageing in humans include, progressive increase in systolic blood pressure, pulse pressure, pulse wave velocity and left ventricular mass; and increased incidence of coronary artery disease and atrial fibrillation. In United States the proportion of people aged 64 and more is projected to increase from $12.54 \%$ (35 million) of population in 2000 and 19.6\%(71 million) in 2030 [1].

Ageing is a normal physiological process characterized by alterations in cell and tissue structures associated with a reduction in (physical, sexual, mental) functional capacity. There is a graded and progressive reduction in 
the homeostatic reserve function of organs and systems as age advances and is referred to as Homeostenosis [2]. The age related autonomic changes lead to decreased in the baroreflex function and the responses to physiological stressors with increased sensitivity to parasympathetic stimulation of the central nervous system. Age related changes are also seen in the intravascular environment. Increase in fibrinogen, coagulation factors V, VIII, IX and other coagulation proteins are seen without a contemporary increase in anticoagulant factors. Circulating prothrombotic inflammatory cytokines also increased in age and may play a role in the pathogenesis of acute coronary syndromes. Adipose cells associated with obesity are also sources of PAI-1 and inflammatory cytokines. All these changes also potentiate development of atherosclerosis. Changes can be identified during regular routine medical checkups. These changes can be minimized by prescribing suitable diet, rest, minimal exercises [3].

Reproducible age related decreases are seen in rates of early left ventricular diastolic filling, maximal heart rates, maximal cardiac output, maximal aerobic capacity or maximal oxygen consumption ( $\mathrm{VO}_{2} \mathrm{max}$ ), exercise induced augmentation of ejection fraction, reflex responses of heart rate, heart rate variability, vasodilatation in response to beta adrenergic stimuli or endothelium mediated vasodilator compounds. Endothelial cells form a monolayer that lines the entire vascular system. Endothelial cells serve as a semipermeable membrane controlling the transfer of small and large molecules into the anterior wall and through the walls of the capillaries and venules maintain the non thrombogenic blood tissue interface by regulating thrombosis, thrombolysis and platelet adherence, modulate vascular tone and blood flow, metabolize hormone, regulate immune and inflammatory reactions, largely by controlling leucocyte interactions with vessel wall, modify lipoproteins in the artery wall, regulate the other cell types, endothelium is an active participant in the interaction between blood and tissues. Endothelial injury is critical to the initiation of atherosclerosis and the vascular effects of hypertension and other disorders [4].
Hardening of walls of arteries because of accumulation of fat deposits and other substances is called Atherosclerosis. Atherosclerosis is a chronic inflammatory process of the arterial wall induced by endogenous toxic plasma lipid components. Atherosclerosis is a major initiator of thrombosis related to abnormal vascular flow and loss of endothelial vascular integrity. M onckeberg medical calcific sclerosis, characterized by calcific deposits in medium sized muscular arteries in persons older than 50 years. Atherosclerosis is characterized by intimal lesions called Atheromas or Fibro fatty plaques that protrude into the lumen. It primarily affects elastic arteries (E.g. Aorta, carotid and iliac arteries) and large and medium sized muscular arteries E.g. Coronary and popliteal arteries [5]. The aim of this study was to assess and to compare the blood pressure and lipid profile in normal adult and aged people for estimation of cardiovascular risk levels by aging.

\section{MATERIALS AND METHODS}

Permission from medical ethics committee of the Institute is obtained to select the subject for the present study. Cases are selected from RIM S. All the subjects are examined clinically by physician.20 normal healthy individuals aged between 40 to 49 years are selected as controls. $20 \mathrm{M}$ ales aged 50 to 70 years with hyper tension are taken. Smokers, alcoholic subjects are also included. Patients with Diabetes mellitus, arteriovenous fistula, known case of coronary arterial disease, congenital heart disease were excluded from the study. Blood pressure was recorded by sphygmomanometer. The recordings were recorded at 10am for three days. Average of the readings was calculated to confirm hypertension.

\section{Specimen Collection:}

$3 \mathrm{ml}$ of venous blood was collected and centrifuged at 3000 RPM for 10 minutes for collection of serum. Serum was used for assaying of biochemical parameters like serum cholesterol, Triglycerides and HDL cholesterol. These are estimated using enzymatic kits on visible spectrophotometer. 


\section{RESULTS AND TABLES}

Table 1: Comparison of Age of control and subjects.

\begin{tabular}{|c|c|c|c|c|c|c|}
\hline & \multicolumn{2}{|c|}{ CONTROLS } & \multicolumn{2}{c|}{ SUBBECTS } & & \\
\hline & MEAN & SD & MEAN & SD & T-VALUE & P-VALUE \\
\hline $\begin{array}{c}\text { AGE } \\
\text { (YEAR) }\end{array}$ & 45.4 & 3.16 & 59.1 & 7.44 & -5.823 & $0.000 ; 5$ \\
\hline
\end{tabular}

The mean age group of controls $45.4 \pm 3.1$ years is less than the subjects $59.1 \pm 7.44$ years and the " $P$ " value is statistically significant.

Table 2: Comparison of BMI values of controls and subjects.

\begin{tabular}{|c|c|c|c|c|c|c|}
\hline \multirow{2}{*}{} & \multicolumn{2}{|c|}{ CONTROLS } & \multicolumn{2}{c|}{ SUBJECTS } & \multicolumn{2}{c|}{} \\
\cline { 2 - 7 } & MEAN & SD & MEAN & SD & T-VALUE & P-VALUE \\
\hline $\begin{array}{c}\text { BMI } \\
(\mathrm{Kg} / \mathrm{m} 2)\end{array}$ & 24.6 & 1.62 & 24.03 & 2.64 & 0.57 & $0.583 ; \mathrm{S}$ \\
\hline
\end{tabular}

The mean BMI of controls is $24.6 \pm 1.6 \mathrm{~kg} / \mathrm{m}^{2}$ is higher than subjects $24.03 \pm 2.64 \mathrm{~kg} / \mathrm{m}^{2}$ and the "P"value is statistically significant.

Table 3: Comparision of HR values of controls and subjects.

\begin{tabular}{|c|c|c|c|c|c|c|}
\hline & CONTROLS & SUBJECTS & \multicolumn{3}{|c|}{ EXPERIMENTAL } & \multicolumn{2}{|c|}{} \\
\hline & MEAN & SD & MEAN & SD & T-VALUE & P-VALUE \\
\hline $\begin{array}{c}\text { HR } \\
\text { (Beats } / \mathrm{min})\end{array}$ & 77.5 & 5.79 & 78.5 & 11.24 & -0.212 & $0.837 ;$ NS \\
\hline
\end{tabular}

The mean values of heart rate of controls $77.5 /$ $\min \pm 5.79$ is less than the subjects $78.5 / \mathrm{min} \pm$ 11.2 and " $P$ " value is statistically non-significant.

Table 4: Comparison of SBP AND DBP values of controls and subjects.

\begin{tabular}{|c|c|c|c|c|c|c|}
\hline & \multicolumn{2}{|c|}{ CONTROLS } & \multicolumn{2}{c|}{ SUBJECTS } & & \\
\cline { 2 - 7 } & MEAN & SD & MEAN & SD & T-VALUE & P-VALUE \\
\hline $\begin{array}{c}\text { SBP } \\
(\mathbf{m m ~ o f ~ H g )}\end{array}$ & 115 & 7.07 & 148 & 19.8 & -5.361 & $0.000 ; 5$ \\
\hline $\begin{array}{c}\text { DBP } \\
(\mathbf{m m} \text { of } \mathrm{Hg})\end{array}$ & 84 & 8.43 & 94 & 5.16 & -2.535 & $0.032 ; 5$ \\
\hline
\end{tabular}

The mean value of SBP of controls $115.0 \mathrm{~mm}$ of $\mathrm{Hg} \pm 7.07$ is less than the subjects $148.0 \mathrm{~mm}$ of $\mathrm{Hg} \pm 19.8$ and " $P$ " value is statistically significant. The mean value of DBP of controls 84.0 $\mathrm{mm}$ of $\mathrm{Hg} \pm 8.43$ is less than the subjects 94.0 $\mathrm{mm}$ of $\mathrm{Hg} \pm 5.16$ and " $\mathrm{P}$ " value is statistically significant.
Table 5: Comparison of serum cholesterol, serum triglyceride, serum HDL among controls and subjects.

\begin{tabular}{|c|c|c|c|c|c|c|}
\hline & \multicolumn{2}{|c|}{ CONTROLS } & \multicolumn{2}{c|}{ SUBJECTS } & & \\
\cline { 2 - 7 } & MEAN & SD & MEAN & SD & T-VALUE & P.VALUE \\
\hline $\begin{array}{c}\text { SERUM CHOLESTEROL } \\
\text { (mg/dl) }\end{array}$ & 162.1 & 21.19 & 21.4 & 25.5 & -3.722 & $0.001 ; S$ \\
\hline $\begin{array}{c}\text { SERUM TRIGLYCERIDES } \\
\text { (mg/ dl) }\end{array}$ & 155.3 & 39.01 & 258.1 & 32.28 & -7.817 & $0.000 ; S$ \\
\hline $\begin{array}{c}\text { SERUM HDL } \\
\text { (mg/dl) }\end{array}$ & 52 & 9.96 & 93.4 & 15.33 & -6.524 & $0.000 ; S$ \\
\hline
\end{tabular}

The mean value of serum cholesterol of controls $162.1 \mathrm{mg} / \mathrm{dl} \pm 21.19$ is less than subjects $212.4 \mathrm{mg} / \mathrm{dl}+25.5$ and "P" value is statistically significant. The mean value of serum triglyceride of controls $155.3 \mathrm{mg} / \mathrm{dl} \pm 39.01$ is less than subjects $258.10 \mathrm{mg} / \mathrm{dl} \pm 32.28$ and " $P$ " value is statistically significant. The mean value of serum HDL of controls $52.0 \mathrm{mg} / \mathrm{dl} \pm 9.96$ is less than subjects $93.4 \mathrm{mg} / \mathrm{dl}+15.33$ serum $\mathrm{HDL}$ and "P" value is statistically significant.

\section{DISCUSSION}

Age related changes are most marked from 60 years onwards. But the changes start from 3840 years. So, it is observed in the present study that age and BMI values are statistically significant. M artin A. James et.al, [6] studied the ageing changes in an age group comparing of older than 60 years of subjects based on the widening of pulse pressure. In most of the studies the mean of 60 years group is selected. There is not much difference in the resting heart rate (reference table -2) the individual variations indicate an increase in heart rate in more than $50 \%$ of subjects but, the values are not statistically significant. In table- 2 mean values of systolic blood pressure and diastolic blood pressures are compared with statistical analysis. There is rise in systolic blood pressure $14+19.8$ and diastolic blood pressure $94.0 \pm 5.16$. So, the pulse pressure is widened in subjects. These values are similar to Martin A. James et al. [6] the main changes in large arteries are stiffness of elastic tissue, with much thicker and less flexible walls. This causes the increase force of ventricular contraction and systolic blood pressure. In the periphery the connective tissue decreases from skin and subcutaneous with decrease in tissue pressure and peripheral 
resistance. This may be the cause for fall in diastolic blood pressure and widening of pulse pressure indicates compliance of vascular system [7-9].

Ageing is associated with loss of compliance in the aorta and the principal arterial conduits. This loss of compliance is a powerful determinant of cardiovascular risk $[9,10]$. The structural changes in the large arteries of older individuals responsible for loss of compliance were felt to be largely irreversible. Recent evidence suggests a role for circulating nitric oxide (NO) in regulating large artery compliance. Several drug doses have been shown to alter large vessel compliance [9]. These include calcium channel blockers, ACE inhibitors oral nitrates, and the potassium channel opening agent Nicorandil. The increasing recognition that large vessel stiffness plays a central path physiological role in hypertension in older individuals may help to guide clinicians in treating specific sub groups of folder hypertensive where evidence supporting one individual drug dose over another is absent $[10,11]$. The same changes may also be due to increase in serum lipid levels for this serum lipid profile is done in two groups and compared statistics. A significant increase in serum cholesterol, triglycerides, and high density lipoproteins was observed in all subjects. This indicates the risk factor atherosclerosis in ageing for heart attacks and cerebral strokes [1012].

\section{CONCLUSION}

The present study is undertaken to evaluate the cardiovascular changes in ageing in men and compared with the normal men. All the ageing men have the complaint of hypertension but in the normal men it is absent. The heart rate of the subjects and controls is found to be non-significant. The SBP and DBP of the subjects is found to be greater in ageing when compared with normal men due to changes in large arteries which include stiffness of elastic tissue leading to much thicker and less flexible walls. This causes the increase force of ventricular contraction and SBP. The increase in large vessel stiffness plays a central patho physiological role in hypertension in older individuals. The lipid profile of the subjects is greater than the controls due to increase in plasma or serum lipid levels. This indicates the risk factor atherosclerosis in ageing. This is one of the predisposing factors for heart attacks and cerebral strokes.

\section{REFERENCES}

[1]. Braunwald's heart disease. A text book of cardiovascular medicine. Indian edition, VIIedition, part IX, chapter 22: Page 1925.

[2]. RobertN.Foley, patricks, parfrey, clinicl and echocardiographic disease in patients CardioInter, 1995,Jan 47(1):186-192.

[3]. Braunwald's heart disease. A text book of cardiovascular medicine. Indian edition, VIIedition, part IX, chapter 22:Page 1926

[4]. Robbins-pathologic basis of disease (part -A) VI edition, chapter: page: 496

[5]. Robbins-pathologic basis of disease (part -A) VI edition, chapter: page: 499

[6]. M artin A. James; Pamela A.C. Watt; John F. Potter; Herbert Thurston; John D. Swales. Pulse pressure and resistance artery structure in elderly. Hypertension. 1995;26:301-306.

[7]. Stanley S.Franklin M D William Gustin IV, B S; Nathan D. Wong PhD; Martin G. Larson, SCD, Michael A. Weber, M D; William B. Kannel, MD; Daniel Levy, $M D$. Hemodynamic patterns of age related changes in blood pressure. Circulation. 1997; 96:308-315.

[8]. Tschudi, Ph.D; T.F.Luscher, MD. Age and hypertension differently affect coronary contractions to endothelin-I. Serotonin and Angiotensins. Circulation, 1995;91;2415-2422.

[9]. Gerhard M arie: M ary-Anne Roddy: Shelly J.Creagers; Mark A. creager. Ageing progressively impairs Endothelium- Dependent vasodilatation in Fore arm Resistance Vessels of humans. Hypertension. 1996; 27:849-853.

[10]. Andrawis N, Jones D.S, Abernethy Dr. Ageing is associated with endothelial dysfunction in the human fore arm vasculature. Journal American Geriatr Soc. 2000; 48:193-198.

[11]. Mikihiro Kihara, yoshikuni Nakasaka, yoshiyuki M itsui, M itsuo Takahashi and James D. Schmelzer. Ageing differentially modifies sensitivity of nerve blood flow to vaso-contractile agents (endothelinI,noradrenalin and angiotensin-II) sciatic nerve. M ech Ageing Dev. 2000; 114:5-14.

[12]. Turner MJ, CM M ier,RJ Spina, KB Schechtman and AA Ehsani.Effects of age and gender on the cardiovascular responses to isoproterenol.J Gerontol A Biol Sci Med Sci 1999 :54:B393-B400.

How to cite this article: V. S. Bhagyalakshmi, M. V. Sailaja, Vijitha. The Risk Factor Atherosclerosis in Ageing for Heart Attacks. Int J Intg Med Sci 2015;2(7):140-143. DOI: $10.16965 /$ ijims.2015.143 